\title{
A STUDY OF ORIGIN, COURSE AND VARIATIONS OF SUPERIOR MESENTERIC ARTERY AND ITS BRANCHES
}

\author{
Deepa $S^{1}$, Ashalatha P. R2
}

${ }^{1}$ Senior Resident, Department of Anatomy, Government Medical College, Kozhikode, Kerala. ${ }^{2}$ Associate Professor, Department of Anatomy, Government Medical College, Kozhikode, Kerala.

ABSTRACT
BACKGROUND
The aim of the study is to determine the origin, course, branches and the variations of superior mesenteric artery by dissection
method in human cadavers.

Study Setting and Design - A cadaveric study in adult human bodies was conducted in the Department of Anatomy, Government Medical College, Kozhikode, Kerala.

\section{MATERIALS AND METHODS}

50 human cadavers by dissection method.

\section{RESULTS}

Middle colic artery (MCA) arose along with right colic artery in 10\% cases. Right colic artery (RCA) arose with ileocolic artery (ICA) in $2 \%$ and absent in $6 \%$ of cases. In 3 cases, common hepatic artery (CHA) arose from superior mesenteric artery (SMA).

\section{CONCLUSION}

The surgeons should be careful during the liver transplant and colonic surgeries as they may encounter such variations.

\section{KEYWORDS}

Superior Mesenteric Artery, Anomalous Origin of Common Hepatic Artery, Hepatomesenteric Trunk.

HOW TO CITE THIS ARTICLE: Deepa S, Ashalatha PR. A study of origin, course and variations of superior mesenteric artery and its branches. J. Evolution Med. Dent. Sci. 2016;5(104):7660-7663, DOI: 10.14260/jemds/2016/1728

\section{BACKGROUND}

Vascular anatomical variations of the celiac trunk and the superior mesenteric arteries were described by Tandler ${ }^{1,2}$ in 1904 as the result of disorders during embryogenesis. The mesenteric arterial supply is a combination of rich collateral networks and commonly encountered variant anatomy. The effect of normal and variant anatomy has implications on pathology, treatment choices, and planning interventions. A review of anatomic variants will assist in understanding the implications of abnormal anatomy on treatment for diseases associated with the mesentery. Differences arising during several developmental stages in the embryonal process lead to a range of variations in these vascular structures. The Superior Mesenteric Artery (SMA) which is the second ventral branch of the abdominal aorta supplies the distal duodenum, the small intestine, and the large intestine up to the right two thirds of the transverse colon. As it supplies the structures derived from the midgut, it is referred to as the midgut artery. Given the vitally important structures it supplies and the important collaterals it provides to both the celiac and inferior mesenteric artery (IMA), there is a very high morbidity associated with SMA occlusions.

Financial or Other, Competing Interest: None.

Submission 05-11-2016, Peer Review 17-12-2016,

Acceptance 23-12-2016, Published 29-12-2016.

Corresponding Author:

Dr. Deepa $S$,

Senior Resident,

Department of Anatomy,

Government Medical College,

Calicut-673008

Kerala.

E-mail: deepaniko@gmail.com, ashalathapr@rediffmail.com DOI: $10.14260 /$ jemds $/ 2016 / 1728$
The SMA comes off at an acute angle in comparison to the celiac artery. In this aortomesenteric angle, the left renal vein and the fourth portion of the duodenum pass. If this angle is too acute, it may lead to either nutcracker syndrome or SMA syndrome. Variant vascular patterns like the accessory right hepatic artery from SMA, anomalous middle colic artery from proximal segment of splenic artery, accessory left colic artery from SMA underscore the importance of doing vascular studies prior to major abdominal surgery. Mutual connections between superior and inferior mesenteric arterial networks are important in both acute and chronic obstructions of the large intestine.

\section{MATERIALS AND METHODS}

The material examined consisted of 50 formalin fixed cadavers from the Department of Anatomy, Government Medical College, Kozhikode. This study was conducted as a cross sectional study after getting clearance from the Institutional Ethics Committee.

The abdomen was opened by roof top incision. The mesentery of the small intestine in the infracolic compartment was exposed. The oblique attachment of the mesentery of the small intestine on the posterior abdominal wall was traced. The small intestine was turned to the left, the right layer of peritoneum of the mesentery along the line of its attachment to the posterior abdominal wall was cut and stripped from the mesentery. The fat from the mesentery was removed to expose the superior mesenteric artery and its branches. The superior mesenteric artery and its branches to the duodenum, pancreas, jejunum, ileum, ascending and transverse colon were traced. Photographs were taken to document the variations. $^{3}$ 


\section{RESULTS}

The first anatomist who described the branches of superior mesenteric artery was Bartolomeo Eustachi. The SMA is the second ventral branch of abdominal aorta. In all the cases, no abnormal site of origin was observed. In three specimens, the superior mesenteric artery was found to have a common origin with hepatic artery.

The distance between the origin of the celiac trunk and the superior mesenteric artery from the aorta ranged from $5 \mathrm{~mm}$ to $25 \mathrm{~mm}$. The mean was $14.88 \mathrm{~mm}$.

\section{Branches of Superior Mesenteric Artery}

1. Inferior Pancreaticoduodenal Artery- This artery is detected in $60 \%$ of specimens and in the rest of the specimens it is either absent or undetectable.

2. Intestinal Branches- The number of ileal and jejunal branches in the present study varied from 8 to a maximum of 15.8 branches were found in 7 cadavers, 9 in 5 cadavers, 10 in 11 cadavers, 11 in 9 cadavers, 12 branches in 9 cadavers, 13 in 7 cadavers and 15 branches in 2 cadavers.

3. Middle Colic Artery (MCA)- In the present study, middle colic artery was found in almost all the cadavers. The artery arose as a separate vessel in most of the cadavers. Middle colic artery also arose as a common trunk with right colic artery in 5 cadavers (Fig. 1).

4. Right Colic Artery (RCA)- The right colic artery arises directly from superior mesenteric artery in 41 cadavers. In 5 specimens, the right colic artery arose as a common trunk with middle colic artery (Fig. 1). In one cadaver, the artery arose along with ileocolic artery as a common trunk (Fig. 3). In 3 cases, the right colic artery was absent (Fig. 2). In those cases, the ascending colon was supplied by branch from the middle colic artery.

5. Ileocolic Artery (ICA)- In 49 cadavers, the ileocolic artery arises directly from the superior mesenteric artery as a separate vessel. Only in 1 cadaver, the ileocolic artery arose in common with right colic artery (Fig. 3).

\section{Unusual Branches}

As mentioned previously in 3 cadavers, the superior mesenteric artery arises along with hepatic artery as a common trunk which is called the hepatomesenteric trunk. This accounts to about $6 \%$ of the total cases (Fig. 4 ).

The common hepatic artery passed behind the portal vein and then divided into right and left hepatic artery. The celiac trunk gave rise to only left gastric and splenic arteries which is named as gastrosplenic trunk.

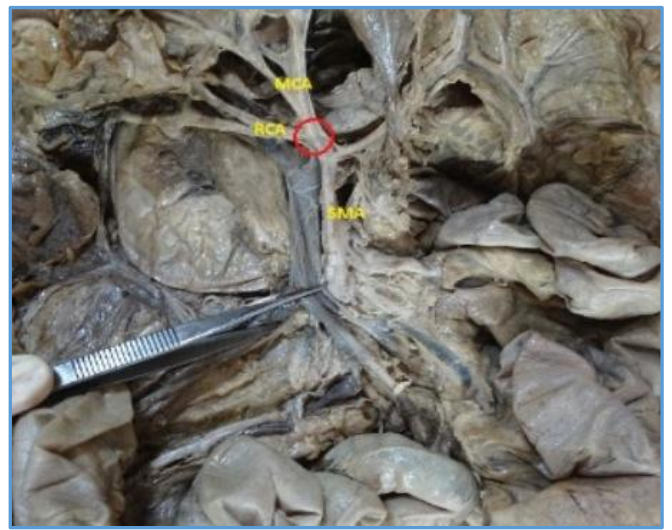

Figure 1. MCA and RCA arose by Common Trunk (red circle)

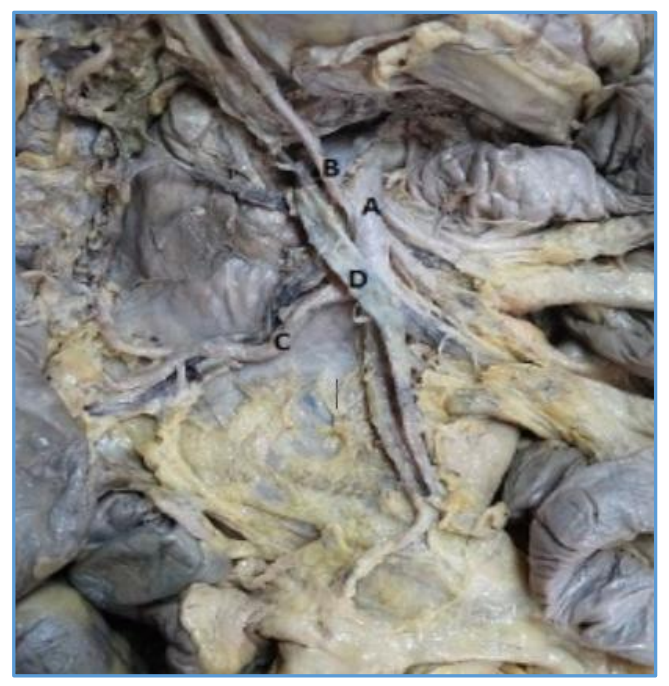

Figure 2. Absence of RCA

$A$ - SMA, B - MCA, C - ICA, D - SMV

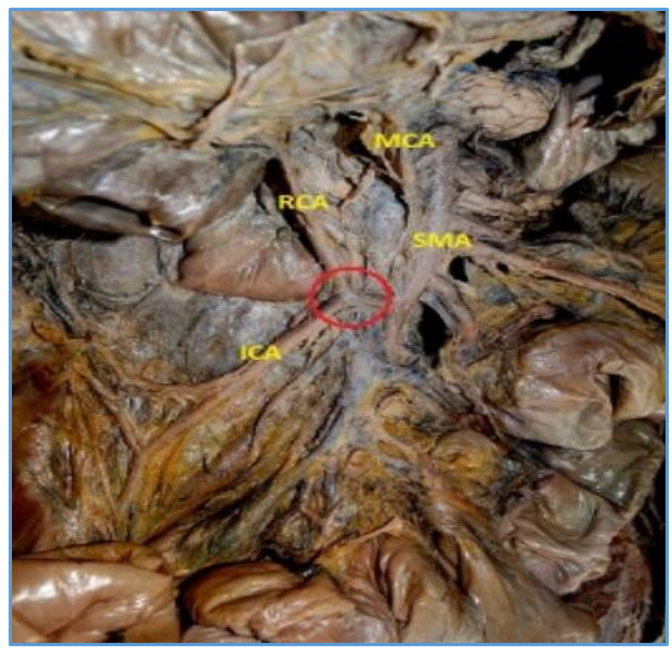

Figure 3. Red circle shows Common Trunk of origin of RCA and ICA 


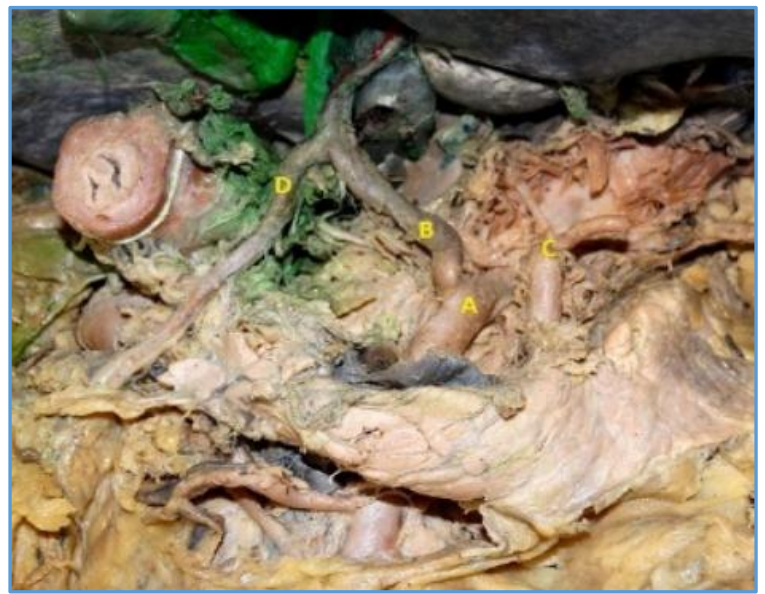

Figure 4. Common Hepatic Artery arising from SMA. ( A - SMA, B - Common Hepatic artery, C - celiac trunk, D - gastroduodenal artery)

\section{DISCUSSION}

During foetal development, both primitive dorsal aortae provide three sets of paired segmental branches, viz., a ventral set for the gastrointestinal tube, a somatic intersegmental set to the body wall and the neural tube and a lateral splanchnic set for derivatives of the intermediate mesoderm. After fusion of the dorsal aortae craniocaudally, the ventral branches are also fused to form a series of unpaired segmental vessels which divide into ascending and descending rami along the dorsal aspect of the developing gastrointestinal tube and eventually forms a dorsal and ventral anastomosis along the gut. Due to such extensive anastomosis, the need of numerous ventral splanchnic branches reduces and ultimately only three trunks persist, namely the coeliac trunk for the foregut, superior and inferior mesenteric arteries for the midgut and hindgut, respectively. Retention or disappearance of any of these arteries results in arterial variations of coeliac trunk or superior mesenteric artery or inferior mesenteric artery. 4

The distance between celiac trunk and superior mesenteric artery was measured as $14.88 \mathrm{~mm}(5-25 \mathrm{~mm})$ by Ozan ${ }^{5,6}$ et al (1997) as $17.9 \mathrm{~mm}$, Yahel 7,6 et al (1998) as $16 \pm 4.0 \mathrm{~mm}$, Ahmet Songur ${ }^{6}$ et al (2010) as $14.34 \pm 2.67 \mathrm{~mm}$ and Nirmaladevi8 et al (2012) as $2-20 \mathrm{~mm}$. The present study coincides with the result of Ahmet Songur 6 et al and it is also close to the numbers observed by Nirmaladevi ${ }^{8}$ et al.

In the present study, the inferior pancreaticoduodenal artery (IPD) was noted in around $60 \%$ of the cases as a single vessel from SMA. In the rest of the cases, it was either undetectable or absent. According to R. Ferrari ${ }^{9}$ et al (2007) IPD was either absent or not assessable in $8.3 \%$ cases, double trunk in $5 \%$, as common trunk in $83.3 \%$ and a single vessel in $3.3 \%$. Michels N $\mathrm{A}^{10,11}$ (1963) says in most instances (60\%) IPD arises as a single vessel from right side of SMA. Thus, the present study goes along with Michels N A ${ }^{10,11}$ (1963).

The number of intestinal branches that were noted in the present study ( 8 - 15) was almost in the same range as that reported by Hollinshead ${ }^{11,12}$ (1962) - 10 to 16 and Ferrari ${ }^{9}$ et al (2007) - 6 to 13. Anozeng Oyono Igiri ${ }^{13}$ et al (2010) reported the no. of jejunal branches ranged between $1 \& 2$ and ileal branches between $5 \& 15$. Michels N A ${ }^{10,11}$ (1963) observed a range of $12 \& 20$.

In the present study, $90 \%$ of the cadavers had MCA arising from SMA as an independent artery. This is in accordance with the study done by Dr Ashwini ${ }^{14}$ (2013) which comes to $90 \%$.
In the study done by Stainslaw ${ }^{15}(2012)$, almost all the cases had MCA arising independently from SMA while this number is very low in the review by Ronald A Bergman. ${ }^{16,17}$ Middle colic artery is also frequently found to be arising as a common trunk with RCA. Present study gives a frequency of 10\% (Fig. 1) which coincides with Dr Ashwini14 (2013). Hollinshead ${ }^{11,12}$ (1962) and Randall18 (2015) have noted up to $50 \%$ of cases while Ronald A Bergman 16 observed this in $25 \%$ of the cases.

The frequency with which the right colic artery arises from superior mesenteric artery independently was $82 \%$ in the present study while it was 38\% in the study by Michels N A,10,11 46\% by Dr Ashwini, 14 28\% by Ronald A Bergman, 16,17 38\% by Randall 18 63\% and $40 \%$ by Arvinder Pal Singh ${ }^{19}$ and Steward.17,20 Right colic artery is said to arise in common with MCA or ICA more commonly. Thus, in the case of Michels N $A^{10,11}$ (1963) and Randall18 (2015), in more than $50 \%$ of cases RCA was arising along with MCA as a common trunk, while in the present study, only in $10 \%$ of the cases there was a common trunk for RCA and MCA (Fig. 1), which goes along with the finding of Dr Ashwini ${ }^{14}$ et al (2013). The RCA also arises along with ICA as a common trunk which was noted in $2 \%$ of the present study (Fig. 3). The number of cases in which RCA was found to be absent in the present study was $6 \%$ (fig:2) which was almost close to that of Randall16 (2015) $10 \%$ and Dr Ashwini 14 et al (2013) - $<10 \%$.

Ileocolic artery is the most constant branch among all the colic branches of SMA. It usually arises as an independent artery from SMA or along with RCA as a common trunk. In the present study, only one case $(2 \%)$ had the common trunk between ICA and RCA (fig:3) while the other cadavers showed the presence of single ileocolic artery independently from SMA. Dr Ashwini ${ }^{14}$ reported an incidence of 34\%.

In the present study, other variations seen were common hepatic artery arising from SMA (Fig. 4). Common hepatic artery from SMA falls under type IX of Michels N A ${ }^{2,21}$ (1955) and type V of Hiatt's ${ }^{22}$ (1994) classification of hepatic arteries. (See table 1).

\begin{tabular}{|c|c|}
\hline Study (Year) & CHA from SMA \\
\hline Michels N $\mathrm{A}^{2,21}(1955)$ & $4.5 \%$ \\
\hline Hiatt's $^{22}(1994)$ & $3.6 \%$ \\
\hline Tharao M K $^{23}(2007)$ & $4.9 \%$ \\
\hline M S Ugure $^{24}(2010)$ & - \\
\hline Hazirolan $^{25}(2009)$ & $2.5 \%$ \\
\hline Eleazar Chaib $^{26}(2010)$ & $1.6 \%$ \\
\hline Present study (2015) & $4 \%$ \\
\hline \multicolumn{2}{|c|}{$\begin{array}{c}\text { Table 1. Comparison of Origin } \\
\text { of Common Hepatic Artery }\end{array}$} \\
\hline
\end{tabular}

The frequency of common hepatic artery originating from SMA in the present study coincides with other studies.

\section{CONCLUSION}

The present study was conducted in the Department of Anatomy, Government Medical College, Kozhikode, Kerala. A total of 50 adult cadavers were dissected to study the origin, course and branches of SMA and IMA and the variations were noted. The findings of the study can be summarised as follows:

1. The SMA in all 50 cases arose from aorta.

2. The inferior pancreaticoduodenal artery was made out in $60 \%$ of cases from SMA. 
3. Intestinal branches were 8 - 15 in number.

4. Middle colic artery arose from SMA independently in $90 \%$ of cases and along with RCA in 10\% cases.

5. Right colic artery arose independently from SMA in $82 \%$, along with MCA in 10\%, with ICA in $2 \%$ and absent in $6 \%$ of cases.

6. Ileocolic artery arose from SMA independently in $98 \%$ and with RCA in $2 \%$ of cases.

7. In 3 cases, common hepatic artery arose from SMA.

Keeping in mind such possible variations the surgeons should be careful during the surgeries of liver transplant and colonic surgeries. In cases where the marginal artery is not continuous the arterial ligation in colon surgeries may lead to ischaemia. So an arteriogram is a must before doing surgeries to avoid complications.

\section{Acknowledgements}

I express my sincere gratitude to the following people who helped me with the workup of this article.

1. The head of the Department of Anatomy of Calicut Medical College for allowing me to do the workup in the department.

2. My guide for her constant encouragement all through the research.

3. My colleagues and the technicians for their support.

\section{REFERENCES}

1. Tandler, J. Zurentwickelunggeschicte des menschlidendar marterien. Anat Hefte 23, 189-209, 475-499.

2. Ognjanović N, Jeremić D, Zivanović-Mačužić I, et al. MDCT angiography of anatomical variations of the celiac trunk and superior mesenteric artery. Arch Biol Sci Belgrade 2014;66(1):233-40.

3. Romanes GJ. The abdominal cavity. Cunningham's manual of practical anatomy. Thorax and Abdomen. $15^{\text {th }}$ edn. London: Oxford University Press 1986:135-8.

4. Indrajit G, Ansuman R, Pallab B. Variant origin of the middle colic artery from the gastroduodenal artery. International Journal of Anatomical Variations 2013;6:13-7.

5. Ozan H, Alemdaroglu A, Sinav A, et al. Location of the ostia of the renal arteries in the aorta. Surg Radiol Anat 1997;19(4):245-7.

6. Songür A, Toktaş $\mathrm{M}$, Alkoç $\mathrm{O}$, et al. Abdominal aorta and its branches: morphometry - variations in autopsy cases. Eur J Gen Med 2010;7(3):321-5.

7. Yahel J, Arensburg B. The topographic relationships of the unpaired visceral branches of the aorta. Clin Anat 1998;11(5):304-9.

8. Nirmaladevi M, Seshayyan S, Rajila RHS. Study of origin of superior mesenteric artery in south Indian population original study with review of literature. Anatomica Karnataka 2012;6(2):33-7.

9. Ferrari R, De Cecco CN, Iafrate $F$, et al. Anatomical variations of the coeliac trunk and the mesenteric arteries evaluated with 64-row CT angiography. Radiol Med 2007;112(7):988-98.
10. Michels NA, Siddharth P, Kornblith PL, et al. The variant blood supply to the small and large intestines. Its import in regional resections. A new anatomic study based on 400 dissections, with a complete review of literature. J Internat Coll Surgeons 1963;39:127-70.

11. Kalaimani A, Bharathi G, Hemapriya $K$, et al. A very rare variation of the superior mesenteric artery- a case report. Journal of Evolution of Medical and Dental Sciences 2013;2(23):4120-25.

12. Hollinshead HW. Anatomy for Surgeons. $2^{\text {nd }}$ edn. Vol. 1, Anatomy for Surgeons 1962:494.

13. Igiri AO, Ekong MB, Egemba GO, ET AL. The pattern of arrangements and distributions of the superior mesenteric artery in a Nigerian population. Int J Morphol 2010;28(1):33-6.

14. Ashwini H, Sandhya K, Hatti A, et al. Branching pattern of the colic branches of superior mesenteric artery-a cadaveric study. Int J Biol Med Res 2013;4(1):3004-6.

15. Milnerowicz S, Milnerowicz A, Taboła R. A middle mesenteric artery. Surg Radiol Anat 2012;34(10):973-5.

16. Ronald A. Bergman, Adel K. Affi, Ryosuke Miyaguchi, Illustrated encyclopedia of Human anatomic Variation: Opus 11; Cardiovascular system; Arteries.

17. Parimala N. B. S. Multiple accessory middle colic arteriesa rare case report. Int J Med Health Sci April 2013;2(2):262-5.

18. Randall R, De Martino. Normal and variant mesenteric anatomy. In: Oderich GS. edr. Mesenteric vascular disease. New York, USA: Springer Science 2015;17. P. 468.

19. Batra APS, Kaur J, Parihar D, et al. Variations in origin of right colic artery supplying colon. 2013;2(1):14-20. http://www.cibtech.org/cjs.htm

20. Steward JA, Rankin FW. Blood supply of the large intestine: its surgical considerations. Arch Surg 1933;26(5):843-91.

21. Michels NA. Blood supply and anatomy of the upper abdominal organs with a descriptive atlas. Philadelphia, Montreal: JB Lippincot Co., 1955:3-137.

22. Hiatt JR, Gabbay J, Busuttil RW. Surgical anatomy of the hepatic arteries in 1000 cases. Annals of surgery 1994;220(1):50-2.

23. Tharao MK, Saidi H, Kitunguu P, et al. Variant anatomy of the hepatic artery in adult Kenyans. Eur J Anat 2007;11(3):155-61.

24. Ugurel MS, Battal B, Bozlar U, et al. Anatomical variations of hepatic arterial system, coeliac trunk and renal arteries: an analysis with multidetector CT angiography. The British Journal of Radiology 2010;83(992):661-7.

25. Hazirolan T, Metin Y, Karaosmanoglu AD, et al. Mesenteric arterial variations detected at MDCT angiography of abdominal aorta. American Journal of Roentgenology 2009;192(4):1097-102.

26. Chaib E, de Souza YEDM, Maruyama MY, et al. Left hepatic artery arising from the superior mesenteric artery: a case study of a rare anatomic variation. The Open Anatomy Journal 2010;2:76-8. 